\title{
PENGGUNAAN BALANCED SCORECARD DALAM STRATEGIC MANAGEMENT JAMU PUSPO
}

\author{
Andre Utoro Pusposuharto ${ }^{1}$ \\ BINUS Business School \\ Dewi Damayani $^{2}$ \\ BINUS Business School \\ Rieke Henriani $^{3}$ \\ BINUS Business School \\ Jimmy Sadeli ${ }^{4}$ \\ BINUS Business School
}

\begin{abstract}
The 'balanced scorecard' is used not only as a tool to clarify the strategy of a company, but more importantly used for planning and development strategies. Without a strategy, it is impossible to survive in a competitive and dynamic business world. Combining long-term competitive capabilities with the goal of creating a synthesized company, the balanced scorecard can be trusted to utilize the financial measures of past performance to predict future performance. This data was analyzed from four perspectives: financial, customer, internal business processes, and learning and growth. The balanced scorecard is used as a basic measure, not only of the company's long-term goals, but also from the inclusion of the vision and mission. Herbal Puspo, a company engaged in the field of herbal pharmaceuticals, is also in the process of determining the direction and objectives of the company.

The authors help determine its vision and mission which is then translated into strategic objectives for the company. The authors collected data and information, including surveys and industry analysis, which is then analyzed using a variety of basic theories of management
\end{abstract}

1. 2, 3 Alumni of BINUS Business School

$4 \quad$ Faculty of BINUS Business School (jsadeli@binus.ac.id)

24) Pusposuharto, Andre U., et al / Journal of Applied Finance and Accounting 4(1) 24-38 
strategies such as Porter's Five Forces and the TOWS matrix. From this analysis, the authors, together with the company management, summarized a strategic measure which was then translated into the four perspectives of the balanced scorecard companies.

Keywords: balanced scorecard, strategic management, Jamu Puspo.

\begin{abstract}
ABSTRAK
Balanced Scorecard dipakai tidak hanya sebagai alat untuk memperjelas strategi sebuah perusahaan, tapi lebih penting lagi dipakai untuk sebuah perencanaan dan pengembangan strategi perusahaan. Tanpa strategi, mustahil sebuah perusahaan dapat bertahan di dunia yang serba kompetitif dan dinamis ini. Penggabungan antara keharusan membuat kapabilitas kompetitif jangka panjang dengan tujuan perusahaan menciptakan sebuah sintesis, dan Balanced Scorecard dipercaya dapat melengkapi ukuran finansial kinerja masa lalu dengan ukuran pendorong (drivers) kinerja masa depan. Semua ini dituang dalam empat perspektif : finansial, pelanggan, proses bisnis internal, serta pembelajaran dan pertumbuhan. Karena itu Balanced Scorecard digunakan sebagai ukuran dasar, bukan hanya dari tujuan jangka panjang perusahaan, tapi juga dari penjabaran visi dan misi yang ditanamkan.

Jamu Puspo, sebuah perusahaan yang bergerak di bidang farmasi herbal juga sedang dalam proses menentukan arah dan tujuan perusahaan. Layaknya sebuah organisasi yang baru berumur lima tahun, Jamu Puspo merasakan sulitnya menggabungkan antara visi dan misi yang ditanamkan pemilik, dengan ukuran pendorong kinerja masa depan.

Penulis membantu menentukan visi dan misi yang kemudian dijabarkan menjadi strategic objectives perusahaan. Penulis mengumpulkan data dan informasi, termasuk berbagai survey dan analisa industri, yang kemudian dianalisa dengan menggunakan berbagai teori dasar strategi manajemen seperti Porter's Five Forces dan TOWS. Dari analisa tersebut, tim penulis bersama dengan tim manajemen perusahaan, merangkum sebuah ukuran strategis yang kemudian dijabarkan dalam empat perspektif Balanced Scorecard perusahaan.
\end{abstract}

Kata kunci: balanced scorecard, strategic management, Jamu Puspo. 


\section{PENDAHULUAN}

PT. Jamu Puspo Internusa (“Jamu Puspo”) adalah sebuah perusahaan berbasis di Jakarta yang bergerak di bidang obat-obatan herbal (jamu) dan makanan/minuman kesehatan. Jamu Puspo didirikan pada tahun 2001 oleh Bapak Tjipto Pusposuharto dan memulai memproduksi produk suplemen kesehatan dari buah mengkudu yang kemudian terkenal dengan nama PACEKAP ${ }^{\circledR}$.

Jamu Puspo lahir sebagai bagian dari Puspa Group yang telah menggeluti bisnis farmasi di Indonesia selama lebih dari 40 tahun. Berbekal pengalaman tersebut, pihak manajemen melihat sebuah celah di bidang industri jamu, yang sebetulnya masih merupakan bagian dari industri farmasi, sebagai salah satu peluang khususnya untuk pasar internasional. Pihak manajemen pusat kemudian mulai membuat konsep produk PACEKAP ${ }^{\circledR}$ yang menjadikan cikal bakal berdirinya sebuah perusahaan dengan nama PT. Jamu Puspo Internusa.

Pada tahun 2001, Jamu Puspo mulai memproduksi dan memasarkan produk PACEKAP ${ }^{\circledR}$, sari buah mengkudu dalam kapsul, yang kebetulan pada saat itu sedang menjadi tren dalam pasar obat herbal. Untuk mendistribusikan produknya, Jamu Puspo kemudian bekerjasama dengan perusahaan distribusi nasional

yaitu PT. Dos Ni Roha yang mempunyai cabang di lebih dari 30 kota di seluruh Indonesia, sehingga produk seperti PACEKAP ${ }^{\circledR}$ langsung tersedia di ribuan apotik, toko obat dan juga supermarket di seluruh Indonesia. Dalam waktu kurang dari satu tahun sejak diluncurkan, PACEKAP ${ }^{\circledR}$ meraih brand awareness dan top-of-mind tertinggi di kateogori makanan suplemen herbal dan menjadi perbincangan di dunia marketing dan media di Indonesia.

Sayangnya sejak menikmati jaman keemasan PACEKAP®, Jamu Puspo terlena dan tidak segera mengeluarkan produk-produk baru. Tercatat di tahun 2002, Jamu Puspo hanya meluncurkan Pace Tea, Hepace, Esinaga, dan Xemin. Pada pertengahan tahun 2003, Jamu Puspo mencoba untuk meluncurkan program marketing besar-besaran untuk mendukung Pace Tea, namun gagal. Produk lainnya seperti Hepace, Xemin dan Esinaga juga tidak berhasil membubuhkan nilai penjualan yang berarti. 
Di tahun 2004, penjualan PACEKAP ${ }^{\circledR}$ mulai menurun drastis. Dibandingkan tahun 2002, penjualan PACEKAP ${ }^{\circledR}$ turun sampai 50\% sehingga pihak manajemen merasa perlu untuk memperbaiki sistim organisasi terutama di divisi marketing yang memiliki jumlah karyawan terbanyak. Namun satu hal yang telah disadari adalah pentingnya bagi perusahaan untuk mengembangkan produk-produk baru dengan cepat. Di tahun 2004, nilai penjualan Jamu Puspo secara total hanya mencatat pertumbuhan sekitar 10\% namun masih jauh di bawah angka di tahun 2002. Praktis angka penjualan Jamu Puspo masih didominasi oleh PACEKAP ${ }^{\circledR}$, dan ditambah oleh pertumbuhan dari Pace Tea ${ }^{\circledR}$. Pihak manajemen kemudian menegaskan kembali visi dan misi sebelumnya yaitu untuk menjadi perusahaan herbal dan fokus kepada produkproduk herbal yang bermutu dan berkualitas, dengan semangat Healthier Life, Happier Living.

Tim marketing kemudian melakukan Internal Environmental Scanning terhadap strategi marketing Jamu Puspo secara keseluruhan. Dengan bantuan firma riset dan konsultan marketing, didapati ternyata brand PACEKAP ${ }^{\circledR}$ masih sangat kuat dan bernilai, kendati nilai penjualannya menurun.

Hasil dari riset menyarankan agar brand PACEKAP® dikembangkan kembali. Di tahun 2005, Jamu Puspo kemudian membuat PACEKAP ${ }^{\circledR}$ Series yang terdiri dari PACEKAP ${ }^{\circledR}$ Reguler $450 \mathrm{mg}$, PACEKAP ${ }^{\circledR}$ Forte 900mg, PACEKAP ${ }^{\circledR}$ Hi-ten untuk Hipertensi, PACEKAP ${ }^{\circledR} \mathrm{Hi}$ ric untuk Asam Urat, PACEKAP ${ }^{\circledR}$ Kolest untuk Kolesterol dan PACEKAP ${ }^{\circledR}$ Diabest untuk Diabetes. PACEKAP ${ }^{\circledR}$ series ini disandingkan juga dengan produk teh celup herbu Pro-Series yang terdiri dari Pro-DeEm ${ }^{\circledR}$ untuk Diabetes, Pro-Siten ${ }^{\circledR}$ untuk Hipertensi, Pro-Murat ${ }^{\circledR}$ untuk Asam Urat, dan Pro-Lestor ${ }^{\circledR}$ untuk Kolesterol ${ }^{\circledR}$.

Di tahun 2006, Jamu Puspo memperkuat tim Pengembangan dan Riset (R\&D) nya untuk mengembangkan produk-produk baru (lihat gambar 3). Antara lain adalah Caldizin ${ }^{\circledR}$, yang diharapkan dapat menjadi salah satu primadona Jamu Puspo, selain itu juga ada Immonugard, suplemen kesehatan tubuh dan Joint Max, suplemen untuk mengatasi rasa nyeri pada persendian yang mempunyai pasar cukup besar. Sampai bulan Juli 2006, Jamu Puspo memiliki 23 brand produk dengan berbagai jenis kemasan. 
Selain itu, Jamu Puspo mulai mencoba memasuki pasar ekspor dengan ikut serta dalam pameran Herbal Asia di Malaysia (2003) dan Indonesia Solo Exhibition di Sharjah-UAE (2004), dan mendapat sambutan yang sangat baik. Pada tahun 2005, Jamu Puspo berhasil menggandeng mitra di Uni Emirat Arab yaitu Assirat Trading Company, dan mengirimkan kontainer pertama dengan produk Noni Tea pada bulan Juli 2005. Selanjutnya, permintaan kerja sama untuk ekspor terus berdatangan sehingga pada tahun 2006 awal, dibentuklah Divisi International Business. Sampai tahun 2006, Jamu Puspo telah menandatangani perjanjian kerja sama dengan Uni Emirat Arab meliputi seluruh negara arab (GCC), Filipina, Amerika Utara (Amerika Serikat dan Kanada), Australia, Taiwan dan Malaysia. Diperkirakan sampai akhir tahun 2006, ekspor Jamu Puspo tahun 2005.

Di aspek produksi, Jamu Puspo juga memperbaiki fasilitas produksi dengan membeli peralatan dan mesin Powder Sachet Filling (pengisi serbuk dalam sachet) untuk Pace Tea, Fluid Bed Dryer (Pengering), Tea Bag Filling (Pengisi kantong teh celup) untuk Pro-DeEm ${ }^{\circledR}$ dan Pro Series lainnya. Di tahun 2003, Jamu Puspo membeli fasilitas ekstraksi herbal. Dengan fasilitas ini, sebagian ekstraksi produk-produk Jamu Puspo mulai dibuat sendiri.

\section{RUMUSAN PERMASALAHAN}

Permasalahan yang dihadapi oleh PT Jamu Puspo saat ini adalah:

1. Perusahaan Masih Tergolong Baru

2. Kurangnya persamaan persepsi dan pengertian tentang Misi, Visi dan Strategi Perusahaan.

3. Tidak adanya Strategic Objective

4. Kurangnya Akuntibilitas Kinerja (Performance Accountability)

5. Tidak adanya penilaian prestasi kerja karyawan yang dihubungkan dengan strategi perusahaan.

\section{LANDASAN TEORI}

SWOT sebenarnya adalah singkatan dari Strength, Weakness, Opportunity, dan Threaths, yang menggambarkan bagaimana peluang 
external (opportunity) dan ancaman (threats) yang dihadapi oleh suatu perusahaan dapat mempengaruhi atau mendukung faktor internal perusahaan yaitu kekuatan (strength) dan kelemahan (weakness). SWOT analysis ini sangat berguna untuk menjabarkan pilihan pilihan untuk para pengambil keputusan dalam perusahaan.

Penting bagi suatu perusahaan untuk mengetahui kekuatan dan kelemahan yang dimilikinya, agar dapat mengidentifikasikan bagaimana posisi perusahaan ini di antara para kompetitornya, apakah lebih baik atau lebih buruk. Apabila lebih baik, bagaimana caranya untuk mempertahankan dan bahkan mengembangkan kekuatan tersebut sehingga dapat meningkatkan performa perusahaan, dan apabila ternyata terdapat kelemahan, apakah yang dapat dan harus dilakukan untuk bisa memperbaiki kelemahan tersebut sesuai dengan permintaan dan kebutuhan konsumen. Oleh Ferrel (1995) disebutkan bahwa "Strengths refer to competitive advantages or distinctive competencies that give the firm and advantage in meeting the needs of its target markets, any analysis of company strengths must be customer focused because strengths are only meaningful when they assist the firm in meeting customer needs", sedangkan penjelasan mengenai kelemahan adalah "Any limitations a firm might face in marketing strategy development or implementation".

Peluang dan ancaman adalah elemen yang terjadi di luar perusahaan, oleh karena itu perusahaan harus selalu waspada terhadap hal hal yang terjadi, yang dapat mempengaruhi perkembangan perusahaan, seperti kondisi politik negara, sosial, ekonomi, budaya, dan sebagainya. Ferrel (1995) menjabarkan peluang sebagai "Favorable environmental conditions that could bring the firm rewards if acted upon properly", sedangkan ancaman dijabarkan sebagai "Conditions or barriers that may prevent the firm from reaching its objectives".

Tujuan dari analisa industri adalah untuk mengetahui faktor faktor eksternal apa saja yang mempengaruhi kondisi dan performa perusahaan. Sebagaimana disebutkan oleh Kotler dan Armstrong (1991) bahwa tekanan dari luar yang dapat mempengaruhi kondisi perusahaan yaitu tekanan demografi, tekanan ekonomi, tekanan alam, tekanan teknologi, tekanan politik, dan tekanan budaya. Lebih lanjut dengan mengacu kepada pendapat Wheelen dan Hunger (2000) bahwa 
Porter's 5 forces terdiri dari ancaman dari pendatang baru (threat of new entrants), persaingan antara perusahaan yang sudah ada (rivalry among existing competitors), ancaman dari produk atau jasa pengganti (threat of substitute products or services), daya penawaran pembeli (bargaining power of buyers), dan daya penawaran pemasok (bargaining powers of suppliers).

Analisa industri dilakukan dengan mengacu pada Porter's 5 forces industry analysis, untuk agar dapat mengkaji dan menilai faktor eksternal eksternal tersebut lebih dalam. Pada masing masing elemen dapat dilihat apakah tekanan kompetisi termasuk tinggi, medium, ataupun rendah. Adapun elemen elemen tersebut adalah ancaman dari pendatang baru, persaingan antara perusahaan yang sudah ada, ancaman dari produk atau jasa pengganti, daya penawaran pembeli, dan daya penawaran pemasok.

Kaplan dan Young (1997) menerangkan bahwa Balanced Scorecard adalah " Suatu set dari target dan hasil kinerja yang digunakan sebagai pendekatan untuk mengukur kinerja yang diarahkan kepada gabungan faktor kritis dari tujuan organisasi." Sebelum ada BSC, banyak perusahaan yang memiliki jabaran dan uraian visi dan misi dari perusahaan, tapi tidak dihubungkan dan dikorelasikan dengan tujuan akhir (goal) misalnya profit atau peningkatan penjualan dari perusahaan tersebut. Seperti yang telah disebutkan oleh Kaplan (1997), bahwa dalam Balanced Score Card, perusahaan dapat dilihat dari 4 perspektif yang berbeda yaitu perspektif keuangan, perspektif pelanggan, perspektif proses bisnis internal, dan perspektif pembelajaran dan pertumbuhan. Kaplan dan Norton juga menekankan bahwa 'learning' is more than 'training'; dimana juga menyangkut hal hal seperti menjadi mentor dalam perusahaan, dan komunikasi yang lancar antara para pekerja sehingga bilamana terjadi permasalahan maka akan dapat diselesaikan dengan cepat. Tiga sumber utama pembelajaran dan pertumbuhan perusahaan datang dari manusia, sistem dan prosedur perusahaan. Juga sebagaimana disebutkan oleh Christopher Mills (2002), bahwa "The scorecard enables companies to track financial results and monitor progress to develop the capabilities and assets for future growth" . Secara keseluruhan, maka dalam balanced scorecard akan terjabar secara detail mulai dari strategi yang akan dilakukan, tujuannya apa, bagaimana cara pengukurannya, target yang harus 
dicapai, dan inisiatif inisitatif apa yang harus dilaksanakan dan diperhatikan oleh perusahaan. Balanced scorecard ini akan dikonstruksikan secara menyeluruh yang dapat diimplementasikan di seluruh korporat perusahaan, hingga diturunkan ke setiap divisi perusahaan sesuai dengan kebutuhan masing masing (Kaplan, 2000).

Strategy Map adalah sebuah diagram yang menunjukan visi, misi, strategi organisasi diimplementasikan dalam aktivitas sehari-hari pada setiap unit bisnis dengan menggunakan KPI (Key Performance Indicator). Strategy Map dibuat dengan menghubungkan strategi obyektif organisasi secara eksplisit dengan masing-masing KPI yang dikelompokan dalam ke empat perspektif balanced scorecard (finansial, pelanggan, bisnis proses internal, dan pembelajaran dan pertumbuhan). Kaplan (2006) memperkenalkan strategy map sebagai transformasi balance scorecard dari sistem pengelolaan kinerja menjadi sistem manajemen strategik.

\section{METODOLOGI PERANCANGAN}

Untuk memulai proses pengembangan balanced score card, penting sekali mengetahui kondisi internal perusahaan tersebut di mata karyawan. Manajemen harus dapat menyetarakan persepsi dan ekspektasi karyawan dan manajemen, agar jalan yang ditempuh oleh karyawan dan management dalam menjalankan roda perusahaan menjadi searah dan seirama.

Untuk mendapatkan gambaran yang jelas mengenai kondisi tersebut di atas, kemudian dilakukan survey intenal terhadap 50 responden karyawan PT Jamu Puspo dengan mendistribusikan kuesioner pada mereka. Responden karyawan tersebut dibagi menjadi beberapa bagian berdasarkan :

a. Tingkat jabatan manager atau staf,

b. Divisi yaitu Marketing, Accounting/Finance/IS, Production/PPIC/R\&D/QC, dan Legal/IT/HRD/Umum;

c. Periode lamanya mereka bekerja di PT Jamu Puspo yaitu: kurang dari 1 tahun, 1 - 3 tahun, $3-5$ tahun, dan diatas 5 tahun. 


\section{HASIL}

Dari survey tersebut dapat disimpulkan bahwa ternyata sebagian besar karyawan tersebut kurang atau tidak memahami visi, misi, tujuan dan bahkan jumlah dari produk yang dimiliki oleh PT Jamu Puspo.

Ternyata banyak pegawai perusahaan yang merasa mengetahui misi dari perusahaan, namun pada kenyataannnya pegawai yang menjawab salah cukup banyak. Yang paling banyak menjawab misi perusahaan dengan benar adalah divisi Marketing diikuti oleh divisi Produksi/PPIC/R\&D/QC.

Berdasarkan data di atas, tidak telalu ada perbedaan pengetahuan mengenai visi perusahaan baik dari level manager ataupun staf, bahkan kelompok staff wanita menjawab paling banyak benar.

Berdasarkan hasil kuesioner untuk mengetahui tingkat pengetahuan karyawan mengenai tujuan perusahaan, ternyata cukup banyak pegawai yang mengetahui secara jelas tujuan dari perusahaan. Bahkan dari kelompok yang telah bekerja antara 3 sampai 5 tahun menunjukan persentase angka yang cukup tinggi yaitu 24\% dan bagi yang bekerja 1 sampai 3 tahun menunjukkan persentase angka sampai dengan $18 \%$.

Berdasarkan data dapat dilihat bahwa pengetahuan pegawai mengenai jumlah produk yang diproduksi oleh perusahaan sangat minim, hal ini terlihat dari rendahnya persentase jumlah pegawai yang menjawab benar. Bahkan dari divisi produk/PPIC/R\&D /QC dan dari divisi marketing masing-masing $2 \%$ dan $4 \%$ yang menjawab benar, sedangkan divisi lain tidak ada yang dapat menjawab dengan benar jumlah produk yang dmiliki

Berdasarkan hasil data survey di atas dapat dilihat bahwa sangat penting bagi PT Jamu Puspo melakukan suatu tindakan yang dapat mengukur secara jelas ,detail dan dapat memberikan gambaran yang tepat mengenai tindakan yang harus dilakukan, serta hasil akhir yang ingin dicapai. Selain itu untuk mendapatkan kesepahaman dalam visi dan misi perusahaan sehingga tujuan akhir perusahaan dapat dipahami bersama dan dapat dicapai. 
Salah satu tujuan awal dari tim adalah untuk mendefinisikan ulang visi dan misi dari Jamu Puspo, agar lebih sejalan dengan tujuan dari perusahaan tersebut. Setelah tim menganalisa visi dan misi yang sudah dimiliki oleh Jamu Puspo, maka telah disimpulkan bahwa visi tersebut tidak terlalu jelas dan fokus arahannya, dimana visi yang disebutkan adalah seperti bayang bayang saja, dan keinginan Jamu Puspo untuk hadir secara global pun tidak jelas. Seiring dengan berjalannya waktu, visi untuk menjadi spesialis di bidang herbal pun sudah tidak sesuai dengan tujuan perusahaan, bahkan tujuan tersebut dapat menghalangi perjalanan Jamu Puspo untuk berkembang lebih luas lagi.

Maka, tim telah merekonstruksikan visi baru untuk Jamu Puspo yang lebih dapat diapplikasikan secara langsung, karena memang sudah disesuaikan dengan kondisi perusahaan, yakni "To become a major player in pharmaceutical, herbal, and consumer health"

Untuk misi yang dapat disesuaikan dengan kondisi perusahaan, tim telah menganalisa bahwa misi yang saat ini dimiliki terlalu panjang sehingga tidak fokus juga, dimana satu pernyataan sebenarnya sudah cukup, dan misi tersebut sebenarnya sudah mengekspresikan misi sebenarnya dari Jamu Puspo, hanya karena terlalu panjang sehingga menjadi tidak jelas maknanya. Oleh karena itu, tim telah merekomendasikan bentuk dari pernyataan misi yang dipersingkat namun tetap mengacu pada misi yang sudah ada tapi dalam bentuk lebih singkat, agar lebih fokus dan terkonsentrasi. Adapun pernyataan misi yang telah direkonstruksi ulang adalah:

\section{"Providing a better health and better life through innovation and creativity and excellence in products and services"}

Struktur organisasi yang saat ini dimiliki Jamu Puspo cenderung lebih luas jangkauan tanggung jawabnya, oleh karena itu, dalam struktur organisasi baru, maka tim telah memperkecil lingkup tanggung jawab dari 7 menjadi 4 divisi yang mempunyai proses yang berdekatan. Hal ini bukan untuk mengurangi cakupan tanggung jawab, namun untuk dapat lebih fokus dalam menjalankan tugas dan memudahkan pengukuran kinerja dari masing-masing divisi. Selain itu, tanggung jawab yang diberikan juga sesuai dengan tujuan strategi (strategic objectives), sehingga kontrol yang lebih baik dapat dilakukan. 
Setelah tim mengumpulkan data dan membuat analisa eksternal dan internal, termasuk diantaranya wawancara dengan pihak pemilik dan direksi, tim berkesimpulan bahwa sangat penting bagi perusahaan untuk memiliki Company Strategic Objectives baik jangka pendek maupun jangka panjang.

1. Jangka Panjang: Melakukan Intial Public Offering (IPO), melakukan Merger dan Akusisi Internal, m elakukan Akusisi Eksternal.

2. Jangka Pendek: membuat obyektif strategis yang dapat digunakan sebagai acuan dalam menentukan Balanced Scorecard. Tujuan strategi ini dibuat dengan target pencapaian di tahun 2010, sehingga tim menamakan Strategic Objectives 2010.

Strategic Objectives Jamu Puspo 2010 adalah meningkatkan revenue, mengembangkan produk baru di luar herbal, melakukan penetrasi pengembangan pasar ekspor, mengimplementasi Program Peningkatan Mutu (Quality Improvement Progam, implementasi standar Cara Pembuatan Obat yang Baik (CPOB), meraih sertifikasi ISO di tahun 2007, mengembangkan dan mengimplementasikan Kendali Mutu yang kuat, mengembangkan dan mengimplementasi ukuran kendali mutu yang lain seperti Six Sigma atau Total Quality Management, melakukan Efisiensi Biaya dan meningkatkan Kompetensi Sumber Daya Manusia. Berdasarkan Tujuan Strategi Jangka Pendek di atas, strategi dapat dirumuskan melalui dua tujuan utama (ultimate strategic goals) yaitu revenue growth dan cost efficiency

Strategi utama dari perspektif finansial adalah meningkatkan shareholder value dengan cara meningkatkan revenue growth melalui peningkatan penjualan baik didalam maupun diluar negeri dan efisiensi biaya melalui perbaikan bisnis proses. Kondisi perusahaan pada saat ini masih merugi dengan tingkat kenaikan penjualan yang masih rendah dan komponen biaya yang masih cukup tinggi. Adanya usaha dari manajemen untuk meningkatkan penjualan dan melakukan penghematan biaya, akan tetapi hasilnya masih belum dapat dirasakan. Hal ini terjadi karena analisa terhadap biaya masih belum dilakukan secara menyeluruh dan tidak adanya keselarasan antara perencanaan strategi dengan implementasi 
Perusahaan masih mengalami kegagalan dalam memenuhi kepuasan pelanggan yang disebabkan oleh kualitas produk yang masih belum stabil, ketersediaan produk dipasar yang pada saat ini masih menjadi hambatan besar serta belum professionalnya pegawai di lapangan sebagai ujung tombak didalam memasarkan produk. Pasar-pasar yang potensial di dalam dan luar negeri yang masih belum tegarap juga menjadi kendala bagi perusahaan. Hal ini diakibatkan oleh belum terfokusnya pasar yang akan dituju dan segmentasi dari pasar itu sendiri.

Dalam mendukung perspektif finansial untuk tercapainya strategi revenue growth yang diterjemahkan sebagai peningkatan penjualan, maka strategi yang harus di kembangkan adalah sebagai berikut:

a. Meningkatkan ketersediaan produk dipasar dengan meningkatkan jumlah distributor, jumlah outlet.

b. Meningkatkan pangsa pasar

c. Memperbaiki logistik dengan meningkatkan kerja sama dengan distributor dalam mengirimkan produk tepat waktu sehingga dapat menjamin ketersediaan produk di pasar sekaligus efisiensi di tingkat perputaran persediaan.

Untuk segi perspektif internal, tingkat utilisasi dari mesin-mesin pabrik yang sangat rendah dan belum optimum (+/- $40 \%$ dari kapasitas produksi ). Jumlah produk cacat yang dihasilkan masih cukup tinggi, perputaran persediaan yang sangat lambat yang sangat membebani perusahaan, serta belum adanya suatu usaha untuk meninjau kembali bisnis proses yang ada dalam Divisi Produksi. Perusahaan saat ini sedang dalam proses untuk menyempurnakan Standard Operating Procedure yang diharapkan dapat diselesaikan sebelum akhir tahun 2006. ERP system yang digunakan perusahaan masih sederhana, sehingga belum dapat mendukung manajemen dan group didalam pengambilan keputusan secara tepat dan cepat, karena belum tersedianya laporan yang dibutuhkan untuk pengambilan keputusan secara cepat yang dapat dihasilkan oleh sistem yang ada, sebagai contoh pengolahan data penjualan yang masih dilakukan secara manual sehingga laporan menjadi tidak uptodate untuk dipakai dalam pengambilan keputusan. 
Dalam mendukung perspektif finansial untuk tercapainya strategi cost reduction dilakukan dengan cara :

a. Implementasi program perbaikan kualitas antara lain dengan :

b. Memperbaiki sistem Production Planning \& Inventory Control (PPIC) untuk meningkatkan utilisasi dari pabrik, mempercepat tingkat perputaran persediaan, dan memelihara persediaan material dan produk yang pada tingkat yang optimum untuk menurunkan tingkat keusangan material dan produk.

c. Meningkatkan riset dan pengembangan dengan mengembangkan formula-formula baru dan jumlah produk yang diregister setiap tahunnya.

d. Implementasi sistem ERP di Accounting dan Production Planning

Untuk mendukung strategi perusahaan diatas, maka tujuan dari pembelajaran dan pertumbuhan adalah dapat memberikan lingkungan kerja yang baik untuk pegawai sehingga perusahaan dapat meningkatkan produktifitas pegawai dan menurunkan tingkat perputaran dari pegawai, dengan cara sebagai berikut:

a. Meningkatkan kompetensi pegawai dengan mengirimkan training pegawai sesuai kebutuhan masing-masing pegawai berdasarkan Analisa Kebutuhan Training. Perusahaan juga akan mengikutsertakan pegawai didalam Corporate University Program

b. Memperbaiki Sistem Kinerja Manajemen/Reward System secara terintegrasi

c. Memperbaiki sistem rekrutmen pegawai

Berdasarkan Strategic Map diatas, maka dibuat suatu ukuran-ukuran yang dipakai untuk mengukur performance dari perusahaan. Balanced Scorecard dibuat untuk Korporat dan setiap Divisi dalam perusahaan sehingga diharapkan kinerja yang diukur akan sejalan dengan strategi perusahaan.

\section{KESIMPULAN}

Dengan adanya Balanced Scorecard, ukuran pendorong utama atau key drivers dari pada ekspektasi penjabaran obyektif strategis perusahaan menjadi jelas. Selanjutnya Balanced Scorecard juga dapat dipakai untuk mengukur kinerja personel dan manajemen yang ada yang lebih jelas dan adil. 
Namun yang lebih penting lagi, Balanced Scorecard ini menjadi satu lini penjabaran dari misi dan visi yang diturunkan menjadi tujuan strategi jangka panjang dan jangka pendek. Dengan demikian, perusahaan mempunyai rencana kerja yang lebih jelas.

Sosialisasi Balanced Scorecard ini juga menjadi kunci keberhasilan utama. Penjelasan tentang visi, misi, dan tujuan perusahaan harus dibuat sedemikian rupa, secara sederhana, dan juga dipastikan agar setiap karyawan di setiap bagian manapun juga di perusahaan mengerti dan bekerja dengan tujuan yang sama (common goal).

\section{DAFTAR PUSTAKA}

Kaplan, Robert S. and Norton, David P., 1996, The Balanced Scorecard: Translating Strategy into Action, Harvard Business School Press, USA.

Kaplan, Robert S. and Norton, David P., 2000, The Strategy-Focused Organization: How Balanced Scorecard Companies Thrive in the New Business Environment, Harvard Business School Press, USA.

Kaplan, Robert S. and Norton, David P., 2006, Alignment: Using the Balanced Scorecard to Create Corporate Synergies, Harvard Business School Press, USA.

Kotler, P. and Armstrong, G., 1991, Principles of Marketing, Prentice Hall, USA.

Mills, Christopher, 2002, Performance Management, Singapore Human Resources Institute, Singapore.

Pride, William M., 1995, Marketing - International Edition, Pride Ferrel, Texas, USA.

Rampersad, Hubert K., 2003, Total Performance Management ; Redefining Management to Achieve Performance with Integrity, Gramedia Pustaka Utama, Jakarta

Ross, S.A., and Westerfield, R., B.D. Jordan, 1993, Fundamentals of Corporate Finance, Irwin,Boston USA. 
Wheelen, Thomas L., and Hunger, J. David, 2000, Strategic Management and Business Policy, Prentice Hall, USA.

38) Pusposuharto, Andre U., et al / Journal of Applied Finance and Accounting 4(1) 24-38 